Research Article

\title{
Study on the Migration Law of Overlying Strata of Gob-Side Entry Retaining Formed by Roof Cutting and Pressure Releasing in the Shallow Seam
}

\author{
Chen Tian, ${ }^{1,2}$ Anhu Wang, ${ }^{3}$ Yingjie Liu $\mathbb{D}^{3},{ }^{3}$ and Tinggui Jia ${ }^{4}$ \\ ${ }^{1}$ Safety Engineering College, Heilongjiang University of Science and Technology, Harbin 150022, China \\ ${ }^{2}$ Bulianta Coal Mine, Shenhua Shendong Coal Group Corporation Ltd., Yulin 719315, China \\ ${ }^{3}$ Emergency Science Research Academy, China Coal Research Institute, China Coal Technology \& Engineering Group Co., Ltd., \\ Beijing 100013, China \\ ${ }^{4}$ Institute of Mining and Coal, Inner Mongolia University of Science \& Technology, Baotou 014010, China \\ Correspondence should be addressed to Yingjie Liu; 290783585@qq.com
}

Received 30 August 2020; Revised 12 November 2020; Accepted 2 December 2020; Published 18 December 2020

Academic Editor: Xianjie Hao

Copyright (c) 2020 Chen Tian et al. This is an open access article distributed under the Creative Commons Attribution License, which permits unrestricted use, distribution, and reproduction in any medium, provided the original work is properly cited.

\begin{abstract}
A mechanical model of a hard roof was built to analyze the pressure relief roof cutting (RCPR) process for gob-side entry retaining (GER) and identify the critical stage of roadway stability control during RCPR. Based on the mechanical analysis of key parameters of automatic roadway with RCPR, the FLAC3D software was adopted to conduct a numerical simulation to investigate the influence law of height and angle of RCPR, to analyze the trend of variations in the vertical displacement of roadway surrounding rock stress and the roof under different conditions, and to verify that the optimal roof cutting height and seam cutting angle of the 12201 working face of Halagou Coal mine are $6 \mathrm{~m}$ and $20^{\circ}$, respectively. The effect of automatic roadway with RCPR has been well implemented through conducting the bidirectional cumulative blasting test on site. To impose effective roadway surrounding rock controlling measures on Halagou Coal mine in RCPR of hard, coal-bearing roof structures at a shallow mining depth, constant resistance large deformation anchor cables, in combination with a single hydraulic prop, joist steel 11\#, and steel mesh reinforcement, could provide active surrounding rock support. In addition to the active support, surrounding rock control could be strengthened using grouting bolts. Based on the result, the stress in the roadway coal side and the vertical displacement of the roof can be reduced through increasing the roof cutting height, contributing to the stability of the roadway. Increasing of the roof cutting angle will lead to the increasing of stress in the coal side of the roadway and the increasing of roof displacement with a maximum angle of $20^{\circ}$. Meanwhile, the peak of stress concentrating on both sides of the extreme angle is decreased. Thus, increasing the cutting roof angle at random can be unfavorable to the management of roadway roof. To develop RCPR GER, roadway surrounding rock requires greater support when the mine face passes through a cutting slot. After industrial trials, these measures are proved to be effective in controlling surrounding rock movement and developing GER.
\end{abstract}

\section{Introduction}

Because of the recent breakthroughs in hydrogen, solar, wind, and other renewable energy technologies, coal energy production has steadily decreased over the years. However, given the present trend of global energy demand, coal resources will remain a main alternative for energy generation for a long time. To improve the extraction rate and efficiency of coal resources, various coal mining problems, such as coal and gas outbursts, gas accumulation, and concentrated stress on the working faces during coal mining, must be solved $[1,2]$. After more than half a century of unremitting efforts by researchers, goaf side-wall roadway retention technology has achieved fruitful practical results [3]. Presently, no-pillar mining has developed into a mature technology $[4,5]$ and is being widely used in the process of coal mining [6]. No-pillar mining technology requires a roadway driving along the empty left lane of goafs to cut the top pressure relief [7]. This 
technique has made encouraging progress in recent years $[8,9]$. Automatic and decompression roadway roof cutting (RCPR) is a novel coal pillar mining technology that can reduce the load transfer from the rock beam to the roadside, thereby improving the stability of the roadway $[10,11]$. This method consists of periodically breaking the cantilever beams weighted ahead of the precrack under the rock beam of the roof $[12,13]$. To implement advanced presplitting along the goaf roadway roof, the empty roadway and stope roof must be cut off from the top of the immediate roof. Then, under the action of the stope roof in the periodic lane, the basic link is cut down along the presplitting surface, enabling the mining of that area and moving the support to the upper strata. This alleviates the stress on the rock surrounding the roadway, thereby improving the roadway stability surrounding the area of rock stress concentration $[14,15]$.

According to the influence of different working face roof lithologies of the retained roadway $[16,17]$ and based on a finite element calculation software result, the top pressure relief is cut to support the stress changes between the bolt and rock masses [18]. Coal seam mining is strongly influenced by the surrounding rock stress changes on the top cut, which releases pressure into the lane [19]. Specifically, based on theoretical research and field practice, the stress of the surrounding rock can cause significant changes in the overburden rock fracture mobility [20-22]. Thus, the broken surrounding rock stress change and movement regularity are particularly important for roadway supporting design. In the Tangshan mine, a grass ditch mineral ore test revealed that $[23,24]$, because of its fully-mechanized coal face with a thin coal seam, the roadway falling height was relatively low, the strata deformation and stress change were relatively small, and low supporting strength was required for the lane. However, this technique is rarely used in coal seams with medium thickness and above because, owing to the large roadway cutting height, large overburden movement deformation, and high stress variation of such coal seams, the technique has many adverse effects on the control of the roadway surrounding the cut rock and roof.

Based on previous research $[25,26]$, this study attempted to determine the critical stage of roadway stability control in the RCPR process by building a mechanical model of a hard roof based on the mechanical characteristics of rock during RCPR. The strata behaviors of the 12201 fully mechanized face in the shallow seam of the Halagou Coal mine have been simulated and studied using the FLAC3D numerical simulation software $[25,27]$. In addition, the change trend of the vertical displacement between the roof and the rock surrounding the roadway was analyzed under different heights and angles of the cutting roof to determine reasonable parameters for the roof cutting height and the seam cutting angle. The effect of roof cutting, verified through field practice, can provide theoretical support and field experience towards a no-pillar mining method for coal using an automatic roadway with RCPR in the Halagou Coal mine. In this study, the pressure in a fully mechanized working face, with a thick coal seam, of the east Halagou goaf ditch coal mine was evaluated near shallow and thin bedrock. Research was conducted regarding the hydraulic jacking cutting method of the mined-out area for upper strata migration. The corresponding supporting technology for the above operation in the thick coal seam is presented, focusing on the cuts that have not yet been performed for the unloading process of more than $7 \mathrm{~m}$ in coal seam mining.

\section{Mechanical Characteristics of Roadway Surrounding Rock during RCPR GER}

In the RCPR GER process, the structure of roadway surrounding rock is altered as the stress on the surrounding rock changes. Before RCPR, the overlying strata maintain high integrity by spreading the load equally. During this stage, no deformation occurs, and the roadway surrounding rock remains stable; see Figure 1(a). The physical connection between the roadway roof and the goaf roof in the cutting slot area is broken because of the presplitting cutting slots in the hard roof [7]. Thus, the hard roof can be remodeled into a cantilever beam. Since the mine face does not move forward, the coal in the hard roof is able to prevent subsidence and deformation; see Figure 1(b).

If the face reaches the cutting slot, roof caving occurs as the overlying strata shed a concentrated load above the roof. This leads to the flap top phenomenon where there is an empty space between the overlying strata and the caving gangue. Meanwhile, the goaf roof is constantly in motion. To achieve successful GER, surrounding rock support must be implemented in this stage; see Figure 1(c). As the face advances, the overlying strata and the gangue in the goaf are gradually compressed and stabilized. During this period, the load carried by the overlying strata is transferred to the deep goaf while other strata in the cutting slot above the roadway are stabilized with anchor cables. The stress on both ends of the roadway is transferred to the integrated coal in the next face and the gangue in the goaf; see Figure 1(d).

Through analysis, the hard roof is simplified to a cantilever beam, and the stress condition is shown in Figure 2(a). In the flap top area, the supporting force of the primary prop is distributed in a triangular form. Considering the end fractures of the hard roof caused by its initial and cyclic movements reach the coal wall [13], the cantilever beam in the coal wall is assumed to be broken when designing the mechanical model of the hard roof. $L_{0}$ is the fracture in the coal wall, and $L$ is the length of the cantilever beam.

If the block rotates around point $\mathrm{O}$ after the flap top fractures,

$$
\begin{aligned}
M_{p}+J \mathcal{\varepsilon} & =M, \\
M_{p} & =\int_{-\left(L_{0}+L_{R}\right)}^{0} p(x) x \mathrm{~d} x, \\
J & =\frac{1}{3} \frac{q\left(L+L_{0}\right)^{3}}{g},
\end{aligned}
$$




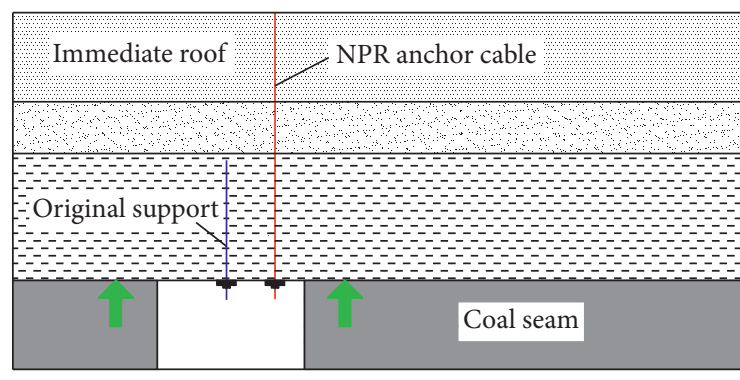

(a)

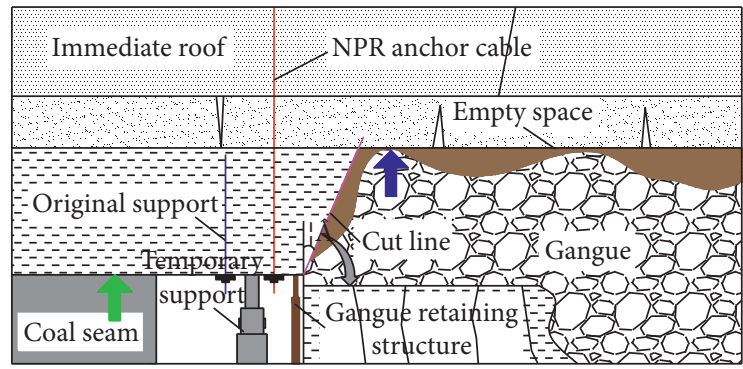

(c)

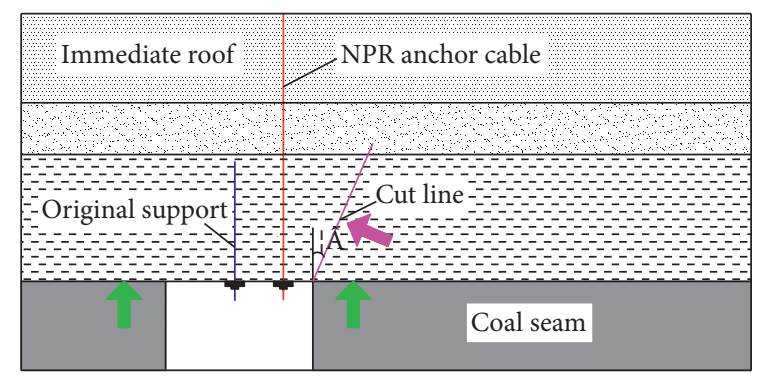

(b)

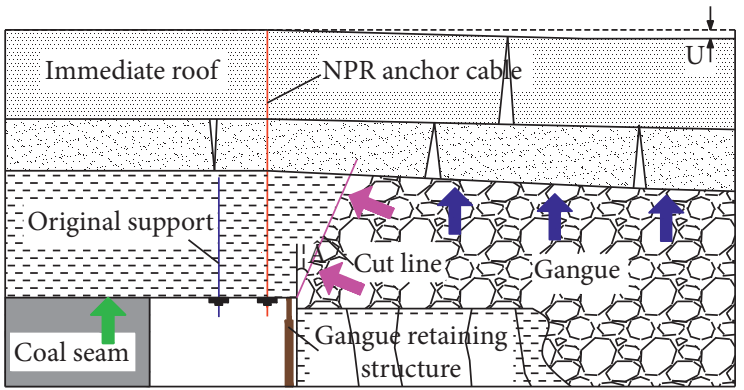

(d)

FIGURE 1: Dynamic structure model of surrounding rock in RCPR GER.

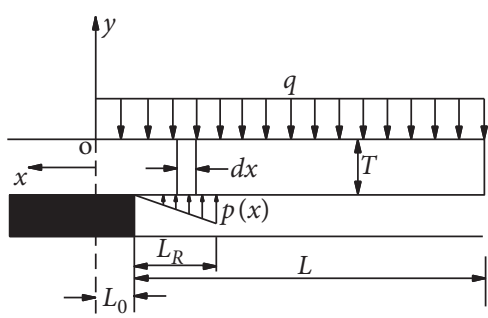

(a)

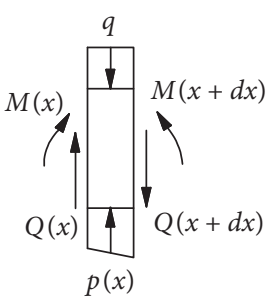

(b)

Figure 2: Mechanical model of hard roof.

$$
M=\frac{1}{2} q\left(L+L_{0}\right)^{2},
$$

with $\mathrm{d} x$ at point $x$ in a given distance from point $\mathrm{O}$ (see Figure 2(b)), then the roof moves forward,

$$
\begin{aligned}
q \mathrm{~d} x+P(x) \mathrm{d} x+\mathrm{d} Q(x) & =\frac{x \varepsilon q \mathrm{~d} x}{g}, \\
\mathrm{~d} M(x)+Q(x) \mathrm{d} x & =J_{\mathrm{d} x} \varepsilon \\
J_{\mathrm{d} x} & =\frac{q \mathrm{~d} x^{3}}{12 g} .
\end{aligned}
$$

The moment $M(x)$ and shear $Q(x)$ borne by the hard roof described in the mechanical model are equal to

$$
\begin{aligned}
& M(x)=\frac{q\left(M_{p}-M\right)}{4 J g} x^{3}-\frac{1}{2} q x^{2}+\frac{1}{2} p(x) x^{2}, \\
& Q(x)=q x-\int_{-\left(L_{0}+L_{R}\right)}^{0} p(x) \mathrm{d} x-\frac{q\left(M_{p}-M\right)}{2 J g} x^{2} .
\end{aligned}
$$

If $x=-\left(L_{0}+L_{R}\right), p(x)=p\left(-L_{0}-L_{R}\right)=P_{n}$, the moment of the roof at the point of cutting can be determined using

$$
M(x)=\frac{\left(P_{n}-q\right)\left(L_{0}+L_{R}\right)^{2}}{2}-\frac{q\left(M_{p}-M\right)\left(L_{0}+L_{R}\right)^{3}}{4 J g} .
$$

The tensile stress applied to the roof is expressed by (11): 


$$
\begin{gathered}
\sigma=\frac{M(x)}{W}, \\
W=\frac{T^{2}}{6} .
\end{gathered}
$$

Tension fracture occurs along the cut line when the tensile stress applied to the roof exceeds its ultimate tensile strength, that is,

$$
\frac{M(x)}{W} \geq[\sigma] .
$$

According to (10)-(13), when tension fracture occurs along the cut line, the roof cutting support resistance $P_{n}$ can be expressed as

$$
P_{n} \geq \frac{2 W[\sigma]}{\left(L_{0}+L_{R}\right)^{2}}+\frac{q\left(M_{p}-M\right)}{2 J g}\left(L_{0}+L_{R}\right)+q .
$$

If the support resistance on the roadside meets the conditions given in (14), the roof may fracture at the roadside support, while the cantilever beam glides down and forms the walls of roadway because of the overlying load and the gravity force.

\section{Geological Conditions of 12201 Working Face}

The 12201 fully mechanized face of Halagou Coal mine is the first mining face of the second panel of coal mine 12\#, with the inclined face of $320 \mathrm{~m}$ in width and of $747 \mathrm{~m}$ in length (from the cutting hole to the stopping line). The GER section is $580 \mathrm{~m}$ in length. As for the face, the coal seam thickness ranges from $0.8 \mathrm{~m}$ to $2.2 \mathrm{~m}$; the average mining height is $2 \mathrm{~m}$; the workable reserves reach $61 \mathrm{Mt}$. The coal seam is relatively stable, with the 12202 face on the northwest, except that there are no other faces nearby. The layout of the 12201 fully mechanized face is as shown in Figure 3.

In terms of the lithology of the 12201 fully mechanized face, the thickness of the overlying bedrock is $55 \mathrm{~m}$ to $70 \mathrm{~m}$, while the unconsolidated layers are $0 \mathrm{~m}$ to $33.48 \mathrm{~m}$ in thickness and $60 \mathrm{~m}$ to $100 \mathrm{~m}$ in depth. The immediate roof of the coal seam is comprised of siltstone that has an average thickness of $1.84 \mathrm{~m}$. The 12 upper coal seam lies above the immediate roof, and its average thickness is $1.56 \mathrm{~m}$. The top of the coal seam contains mudstone with an average thickness of $1.35 \mathrm{~m}$. The main roof of the coal seam consists of fine sandstone and siltstone, whose average thickness is $3.34 \mathrm{~m}$ and $4.05 \mathrm{~m}$, respectively. The immediate floor of the face is made of siltstone with an average thickness of $3.67 \mathrm{~m}$. At the bottom of the immediate floor, there is fine sandstone and its average thickness is $4.23 \mathrm{~m}$. The lithology of the 12201 full -mechanized face is shown in Figure 4.

\section{Analysis of Key Parameters of Automatic Roadway with RCPR}

The roof in goaf is broken and caved after the stopping in the working face. The main roof is formed by the cantilever beam structure at a certain length due to the breaking which resulted from the impact of self-weight after the completion of the first caving. The contact stress between the basic roof and the overlapping rock layer is due to the cantilever roof state. Displacement produced by the contact layer leads to shear damage of the roof, consequently generating large rotational deformation, which enhances the difficulty of roadside supports. Presplitting seams are formed on the roof through automatic roadway with RCPR. The roof is fallen as a whole at the presplitting seam under the periodic weighting effect, which reduces the rotational deformation caused by the shear failure of the roof, hence to control balance in load distribution of the overlying strata and implement the purpose of automatically driving roadway and stabilizing surrounding rock.

The actuality of goaf in the 12201 fully mechanized face of the Halagou Coal mine is simplified as a mechanical model of the roof cutting height, as shown in Figure 5. The tensile stress assumed by the not through face plays a critical role in roof cutting. The larger the roof cutting height is, the greater the tensile stress assumed by the not through face. In this way, the not through face can be cut smoothly, while the roof above goaf will cave completely. Key decisive parameters for smoothly cutting of the immediate roof can be guaranteed by determining reasonable heights of roof cutting. According to the rock fragmentation theory [21, 22], formula (15) is applied to calculate the roof cutting height.

$$
L_{Q}=\frac{\left(H_{1}-H_{2}-H_{3}\right)}{K-1} .
$$

When RCPR is conducted on the roof with zero deflection, the roof cannot be caved completely since large vertical stresses are generated by the roof above goaf, which leads to stress concentration. A certain seam cutting angle can be selected. The roof caving effect of the goaf [25] can be profoundly affected with the angle effect.

The goaf in the 12201 fully mechanized face of the Halagou Coal mine is simplified into a mechanical model with seam cutting angle, as shown in Figure 6. Since the roof is deformed and sunken due to the effect of the overlying rock gravity $q$, extrusion friction $\tau$ will be generated at the seam cutting, which should be reduced in order to implement the smooth subsiding of the roof through completing the roof cutting. That is, the roof will fall when $q L>\tau$ [25]. When the cutting seam is inclined, there will be a certain angle at the seam. The extrusion friction at the cutting seam $\tau^{\prime}=\tau \cos \alpha$ is smaller than that at the vertical cutting seam. Different seam cutting effects can result from different seam cutting angles that have large influences on the movement and stress distribution of the overlying rock. Thus, determining a reasonable seam cutting angle will contribute to the completion of roof caving in the working face and balance of the stress distribution.

\section{Rule of Strata Behaviors of Automatic Roadway with RCPR}

5.1. Establishment of the Numerical Model. According to the geological conditions in the 12201 fully mechanized face of 


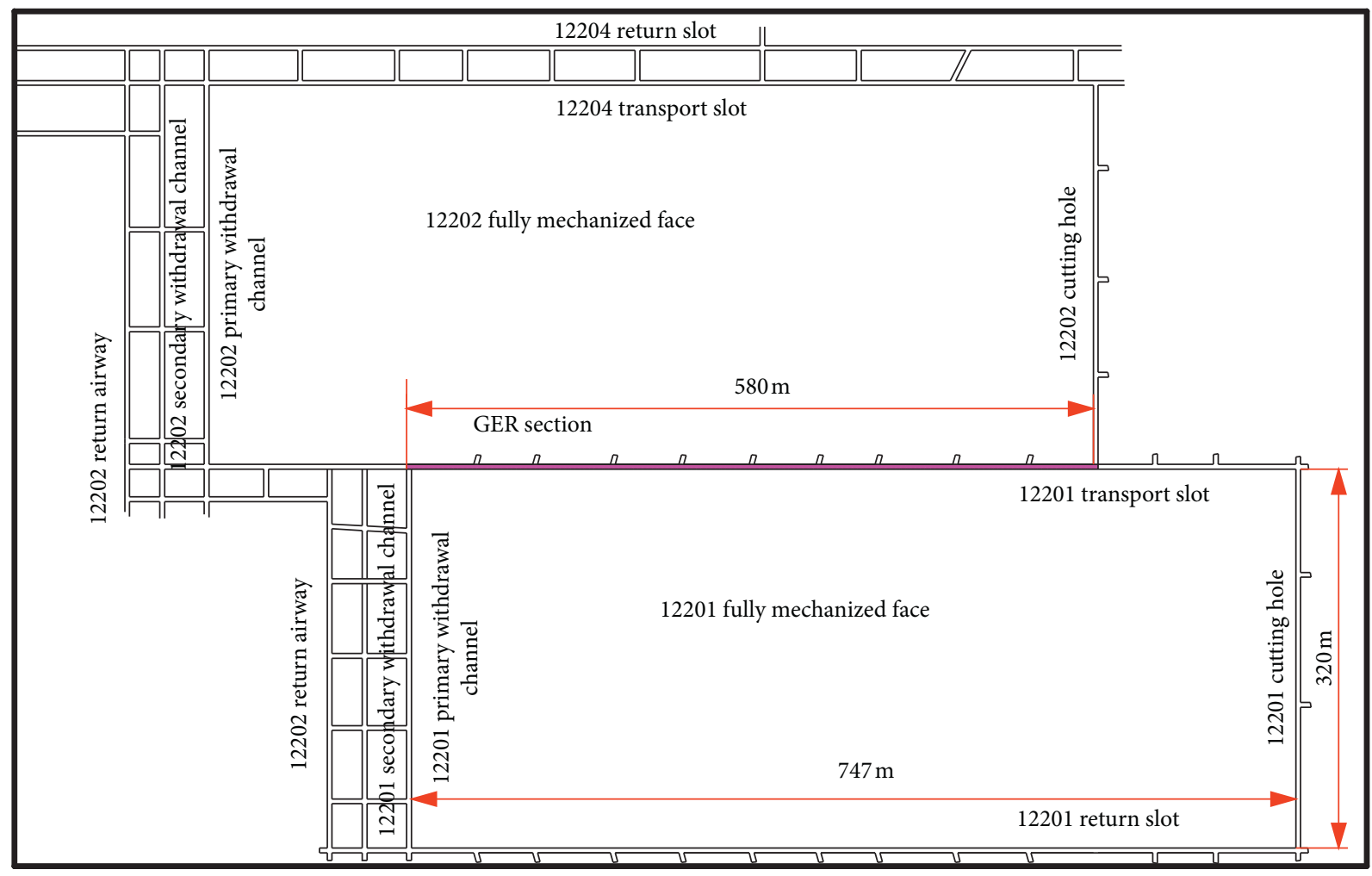

FIgURE 3: 12201 face layout.

\begin{tabular}{|c|c|c|c|c|}
\hline Stratum & No. & Depth of stratum (m) & Histogram & Rock name \\
\hline \multirow{8}{*}{$\begin{array}{l}\text { Yan'an } \\
\text { group }\end{array}$} & 1 & $4.63 \sim 0.03 / 4.05$ & \multirow{4}{*}{ 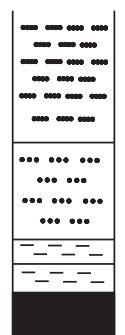 } & Siltstone \\
\hline & 2 & $4.18 \sim 2.50 / 3.34$ & & Fine sandstone \\
\hline & 3 & $2.14 \sim 0.55 / 1.35$ & & Mudstone \\
\hline & 4 & $2.7 \sim 0.00 / 1.56$ & & 12 upper coal \\
\hline & 5 & $3.90 \sim 0.52 / 1.84$ & & Siltstone \\
\hline & 6 & $2.30 \sim 0.80 / 1.92$ & $=-\infty$ & $12 \mathrm{coal}$ \\
\hline & 7 & $10.40 \sim 0.15 / 3.67$ & 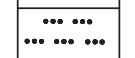 & Siltstone \\
\hline & 8 & $7.75 \sim 2.40 / 4.23$ & $\ldots \cdots \cdots$ & Fine sandstone \\
\hline
\end{tabular}

FIGURE 4: Comprehensive histogram of 12201 fully mechanized mining face.

the Halagou Coal mine, the calculation model is established with the application of FLAC3D numerical simulation software. In the process of automatic roadway formation through roof structure adjustment, the rock surrounding the roadway will be in a state of yielding or plastic flow, whereas the coal and rock far from the free surface will be in an elastic

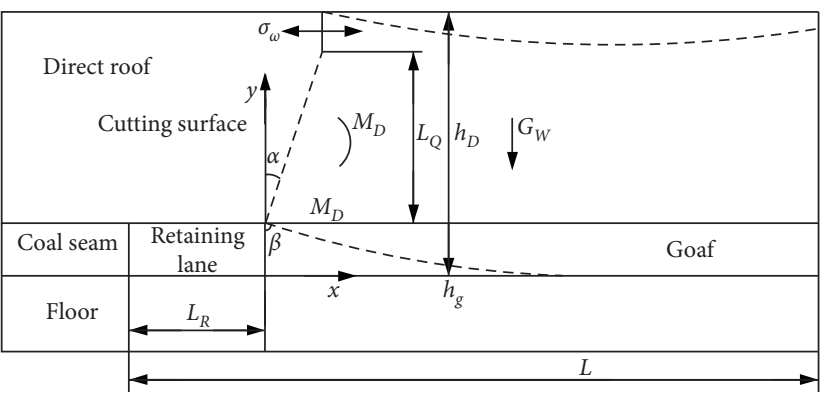

Figure 5: Mechanical model of top roof of cut top height in goaf. $\left(M_{D}\right)$ rotary bending moment. $\left(L_{Q}\right)$ roof cutting height. $\left(h_{D}\right)$ thickness of the immediate roof. $\left(\sigma_{\omega}\right)$ tensile stress of the blind face.

state. Using FLAC3D, the distribution of stress and strain of the rock surrounding the roadway was simulated to analyze their changes and displacements during automatic roof cutting and unloading.

The Mohr-Coulomb constitutive model in the size of $180 \mathrm{~m} \times 60 \mathrm{~m} \times 50 \mathrm{~m}$ is selected. The mining sizes of the simulated roadway and the working face are $5 \mathrm{~m} \times 60 \mathrm{~m} \times 2 \mathrm{~m}$ and $100 \mathrm{~m} \times 60 \mathrm{~m} \times 2 \mathrm{~m}$, respectively. The covered depth of the roadway is $100 \mathrm{~m}$. It is advanced along the roof and the roof is drilled along the roof and the floor of the coal seam. The roof is composed of 2-meter-thick siltstone, 2-meter-thick 12 coaling, 1-meter-thick mudstone, 4-meter-thick fine sandstone, and 4-meter-thick siltstone, from top to bottom; while the floor is composed of 4-meter-thick siltstone and 4-meterthick fine sandstone, from top to bottom; mechanical parameters of strata are presented in Table 1; and the calculation 


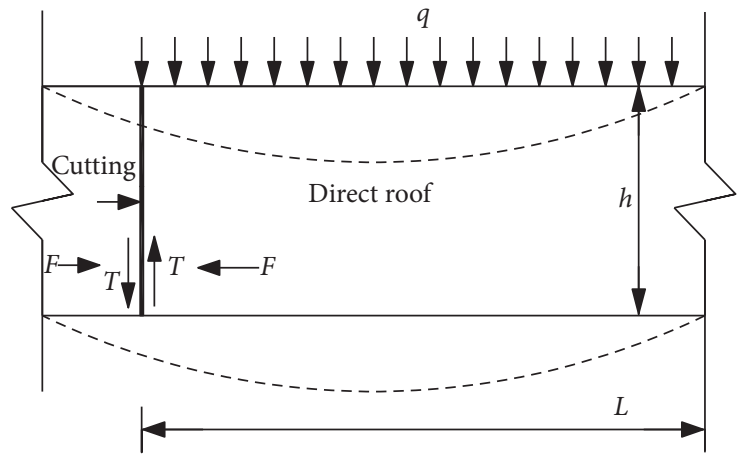

(a)

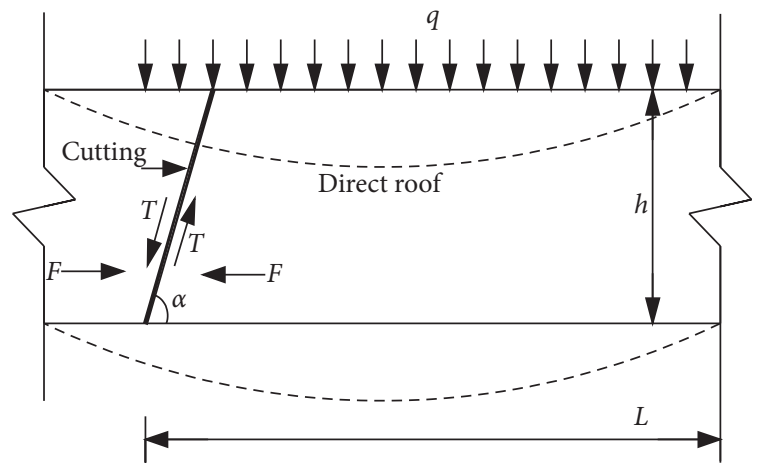

(b)

Figure 6: Mechanical model of angle roof of cutting seam in goaf. (a) Vertical seam cutting. (b) Inclined seam cutting.

model is shown in Figure 7. The displacement of $x$ direction is limited by left-right boundaries of the model, while the displacement of $y$ direction is limited by the forward-backward boundary. Moreover, as the applied horizontal compressive stress is varying with the depth, the displacement of $z$ direction is limited by the lower boundary with the evenly distributed self-weight stress applied on the upper boundary.

5.2. Analysis of Numerical Simulation Results. Distribution characteristics of the vertical stresses of surrounding rocks under different roof cutting heights are given in Figure 8. It can be seen from table that the roof cutting height plays a certain role in transferring the vertical stress of the surrounding rock towards the core of the coal side. The position of stress concentration is transferred to the core part of the coal side. Figure 9 presents distribution characteristics of the vertical displacement of surrounding rocks under roof cutting heights. The vertical displacement of the roadway roof is decreased with the increase of the roof cutting height. Pressure relief effects of different roof cutting heights are shown in Figure 10. Specifically, the stress concentration peaks are at $3.03 \mathrm{MPa}, 2.71 \mathrm{MPa}$, and $2.67 \mathrm{MPa}$ when the roof cutting heights are at $4 \mathrm{~m}, 6 \mathrm{~m}$, and $10 \mathrm{~m}$, respectively. What is more, the influence of the stress concentration area is gradually diminished in the coal side of the roadway, which indicates that the increase of the roof cutting height is favorable to the roadway maintenance. Although it causes the stress concentration area to be away from the roadway side, the influence of the increased height on the position of the stress concentration area is nearly unchanged, since the increased height of roof cutting needs an increased amount of dosing, making the construction more difficult. The maximum values of the vertical displacement of the roadway roof are $101 \mathrm{~mm}, 100 \mathrm{~mm}$, and $97 \mathrm{~mm}$ at the roof cutting heights of $4 \mathrm{~m}, 6 \mathrm{~m}$, and $10 \mathrm{~m}$. The gradually decreased vertical displacement in the roadway roof is beneficial to control the deformation of surrounding rocks of the roof and to maintain the roadway stability.

Distribution characteristics of the vertical stresses of surrounding rocks under different roof cutting angles are presented in Figure 11. It can be seen that the stress concentration area inside the coal side is about $5 \mathrm{~m}$ or $6 \mathrm{~m}$ away from the coal side. The roof cutting angle is essential for maintaining the stability of surrounding rocks in the roadway. Distribution characteristics of the vertical displacement of surrounding rocks under different roof cutting angle are presented in Figure 12. When the roof cutting angles are $10^{\circ}, 20^{\circ}$, and $25^{\circ}$, there will be a large vertical displacement of the roof in goaf. Since there is a low stress area covering a large scope in goaf, a certain splitting angle is favorable to roof caving in goaf, so as to achieve the purpose of filling the goaf and supporting the upper strata with the caved rock mass. The pressure relief effect at different roof cutting angles is shown in Figure 13. It can be observed that the stress concentrating peaks are $3.80 \mathrm{MPa}, 5.21 \mathrm{MPa}$, and $5.15 \mathrm{MPa}$ at the roof cutting angles of $10^{\circ}, 20^{\circ}$, and $25^{\circ}$, respectively. Besides, the influence of the roof cutting angle on the stress concentrating peak is in an extreme relationship. To be specific, the stress concentrating peak is increased with the increase of the roof cutting angle on the left side of the extreme angle of $20^{\circ}$, while the stress concentrating peak is decreased with the increase of the roof cutting angle on the right side of the extreme angle of $20^{\circ}$. When the roof cutting angles are $10^{\circ}, 20^{\circ}$, and $25^{\circ}$, the maximum vertical displacements of the roof are $240 \mathrm{~mm}$, $480 \mathrm{~mm}$, and $500 \mathrm{~mm}$, respectively. The larger the roof cutting angle, the greater the vertical displacement of the roof the interaction between the roof in goaf and the roof in the roadway, which is weakened with the increased angle of roof cutting. Meanwhile, the length of short beams of the roof in the roadway is extended, leading to the increase of roof deformation.

\section{Surrounding Rock Control in RCPR}

6.1. Field Experiment. Key parameters of automatic roadway with RCPR in the 12201 fully mechanized face of Halagou coal mine have been simulated and studied with the FLAC3D numerical simulation software, which confirms that the reasonable roof cutting height and splitting angle are $6 \mathrm{~m}$ and $20^{\circ}$, respectively. The roof condition of Halagou coal mine is complex. The compressive strength of direct roof siltstone, mudstone, and fine-grained sandstone is relatively low. According to the exposure of the roof during 12201 
TABLE 1: Rock layer mechanical parameters.

\begin{tabular}{|c|c|c|c|c|c|c|}
\hline Strata & $\begin{array}{l}\text { Thickness } \\
\text { (m) }\end{array}$ & $\begin{array}{l}\text { Internal friction angle } \\
\left({ }^{\circ}\right)\end{array}$ & $\begin{array}{l}\text { Density } \\
\left(\mathrm{g} \cdot \mathrm{cm}^{-3}\right)\end{array}$ & $\begin{array}{c}\text { Tensile strength } \\
(\mathrm{MPa})\end{array}$ & $\begin{array}{c}\text { Elasticity modulus } \\
(\mathrm{GPa})\end{array}$ & Poisson's ratio \\
\hline Siltstone & 4.0 & 30 & 2.552 & 2.80 & 32 & 0.28 \\
\hline $\begin{array}{l}\text { Fine } \\
\text { sandstone }\end{array}$ & 4.0 & 30 & 2.550 & 2.80 & 32 & 0.28 \\
\hline Mudstone & 1.0 & 30 & 2.301 & 3.53 & 23 & 0.28 \\
\hline 12 upper coal & 2.0 & 30 & 1.462 & 0.60 & 15 & 0.35 \\
\hline Siltstone & 2.0 & 30 & 2.511 & 2.30 & 35 & 0.25 \\
\hline Siltstone & 4.0 & 30 & 2.550 & 2.80 & 32 & 0.28 \\
\hline $\begin{array}{l}\text { Fine } \\
\text { sandstone }\end{array}$ & 4.0 & 30 & 2.514 & 2.30 & 35 & 0.25 \\
\hline
\end{tabular}

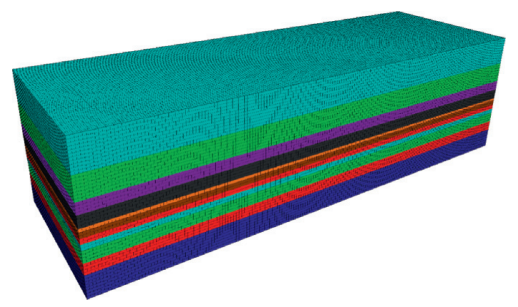

FIGURE 7: Numerical simulation model.

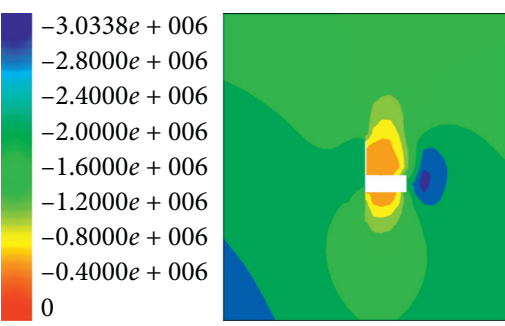

(a)
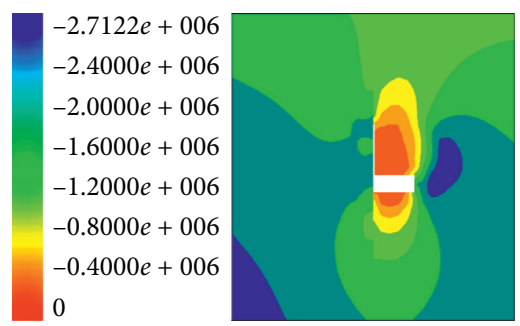

(b)
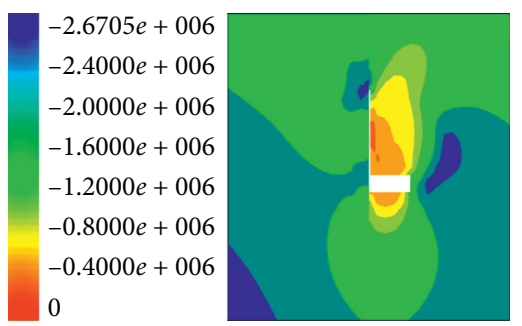

(c)

FIGURE 8: Vertical stress diagram of different cutting heights. (a) $4 \mathrm{~m}$. (b) $6 \mathrm{~m}$. (c) $10 \mathrm{~m}$.
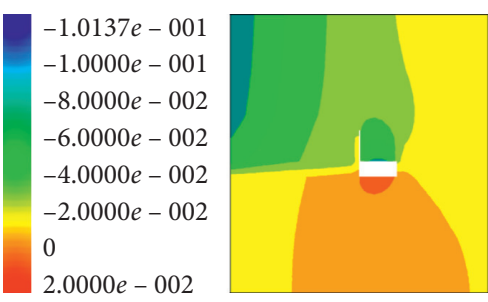

(a)

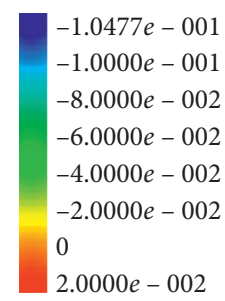

$2.0000 e-002$

(b)

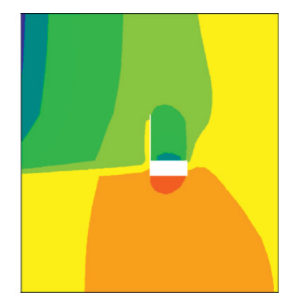

(b)

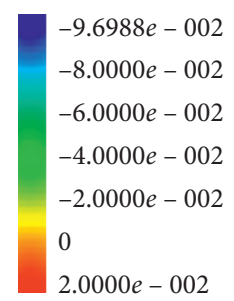

(c)

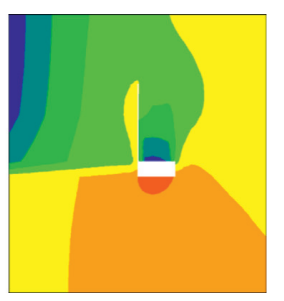

FIgURE 9: Vertical displacement diagram of different roof cutting height. (a) $4 \mathrm{~m}$. (b) $6 \mathrm{~m}$. (c) $10 \mathrm{~m}$.

transport roadway excavation, there are special geological conditions in some parts of the roadway roof, which increase the blasting difficulty. If the conventional blasting method is used, it is bound to cause a large area of roadway roof damage and even the occurrence of roof fall and other serious accidents. The bilateral cumulative tensile explosion technology can protect the integrity of the roof while blasting, and presplit to shape, which can meet the requirements of the design scheme.
Bilateral cumulative tensile explosion was employed in directional roof cutting. As for the underlying mechanism of directional tensile fracture, specifically, two shaped charges were placed into a gathering device with two preset directions of blasting. After detonation, pressure from different directions other than the preset ones was applied uniformly to the surrounding rock around the blasting boreholes, which were in tension in the preset directions at the same time. 


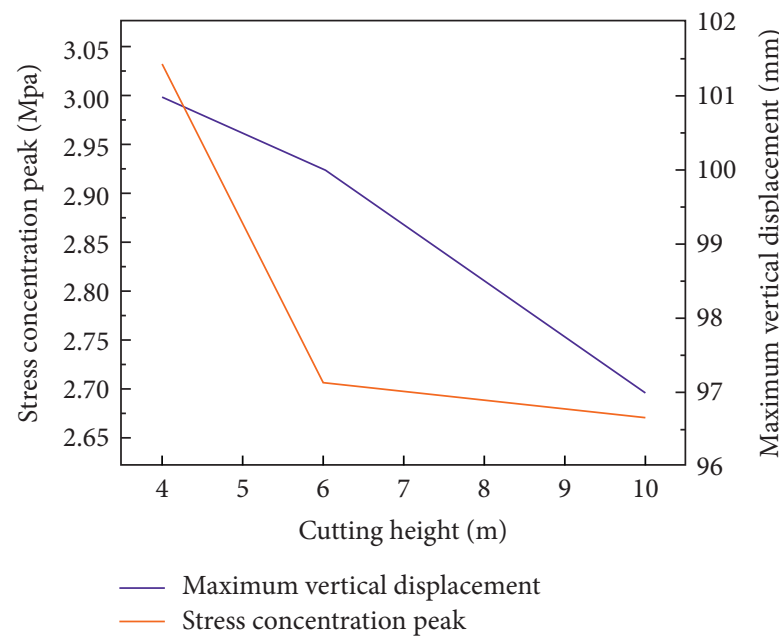

Figure 10: Pressure relief effect of different roof cutting heights.

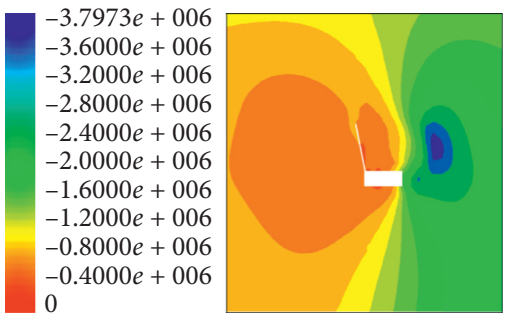

(a)

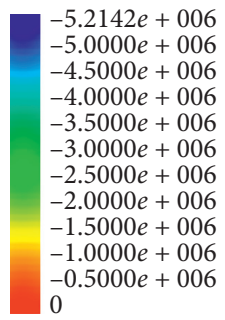

$-0.5000 e+006$

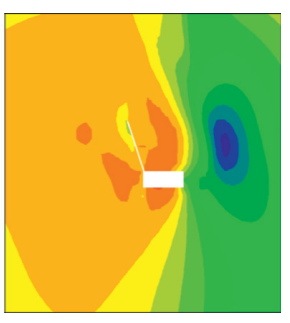

(b)

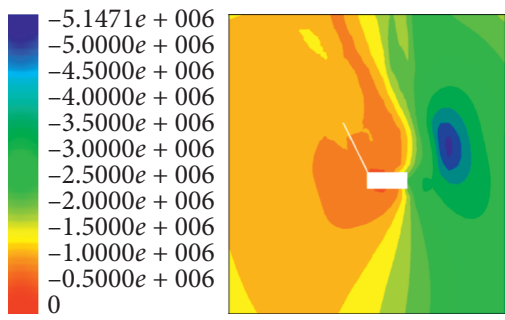

(c)

FIGURE 11: Vertical stress diagram of different roof cutting angles. (a) $10^{\circ}$. (b) $20^{\circ}$. (c) $25^{\circ}$.
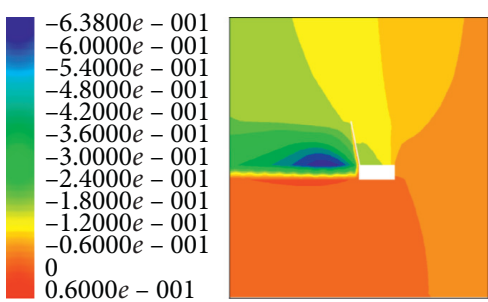

(a)

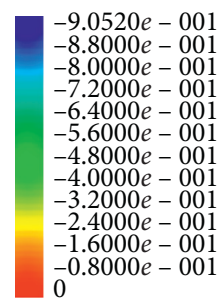

$-0.8000 e-001$

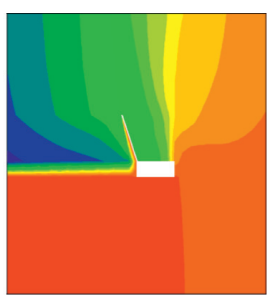

(b)

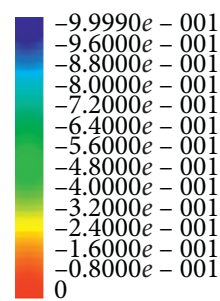

(c)

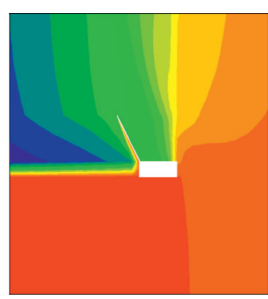

Figure 12: Vertical displacement diagram of different roof cutting angle. (a) $10^{\circ}$. (b) $20^{\circ}$. (c) $25^{\circ}$.

6.1.1. Cutting Height. The cutting height refers to the directional cutting crack of the coal seam roof via directional cumulative blasting technology. The maximum vertical distance from the roof plane of the channel to the upward development of the cutting seam is called the cutting height. Directional blasting to cut the grooving roof is the core part of the pressure relief roof cutting technique along the goaf roadway. A sufficient slit height can ensure that the gangue cut off can support the movement of the old top rock beam of the overlying strata in the goaf. Based on (15), $K$ was set as 1.3. Considering the influence of the wall height and without considering floor heave and roof sinking, the slit height was less than $6.7 \mathrm{~m}$. Considering that the roof of the coal seam in this working face belongs to the composite roof, the roof sinking amount and the floor heave amount at the depth of the precrack slit hole were determined to be $6 \mathrm{~m}$ [28].

6.1.2. Slit Angle. Through the analysis of the actual effect of similar mining conditions, an obvious angle can be observed in the slit, which can affect not only the roof span of the goaf but also the distribution at the stress concentration area. A suitable slicing angle is beneficial to the roof span of the goaf and enhances the stress distribution in the stope. Therefore, the optimal slit angle was determined to be $20^{\circ}$.

In the field test scheme, a single-hole test was performed to determine the optimal charging amount and length of the optimal air column according to the results of the roof peep 


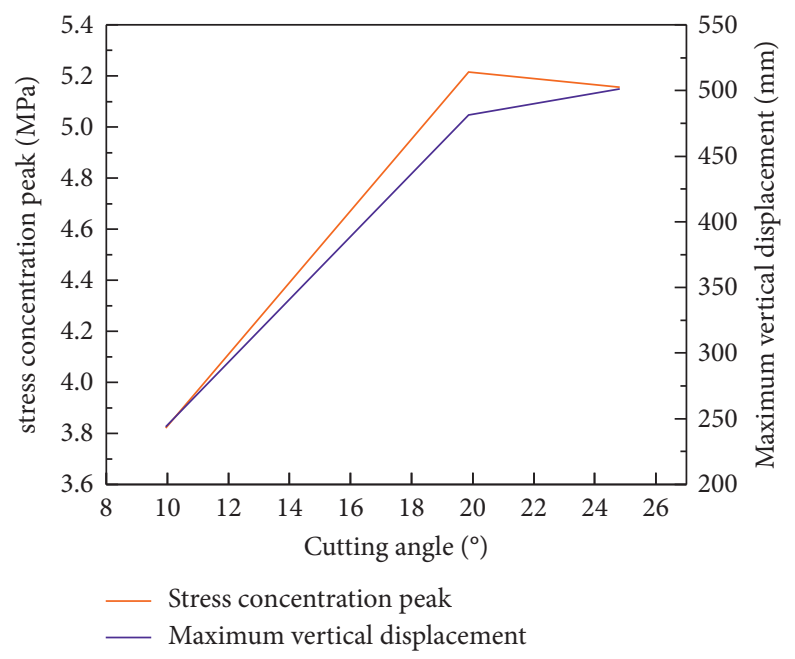

FIGURE 13: Pressure relief effects of different roof cutting angles.
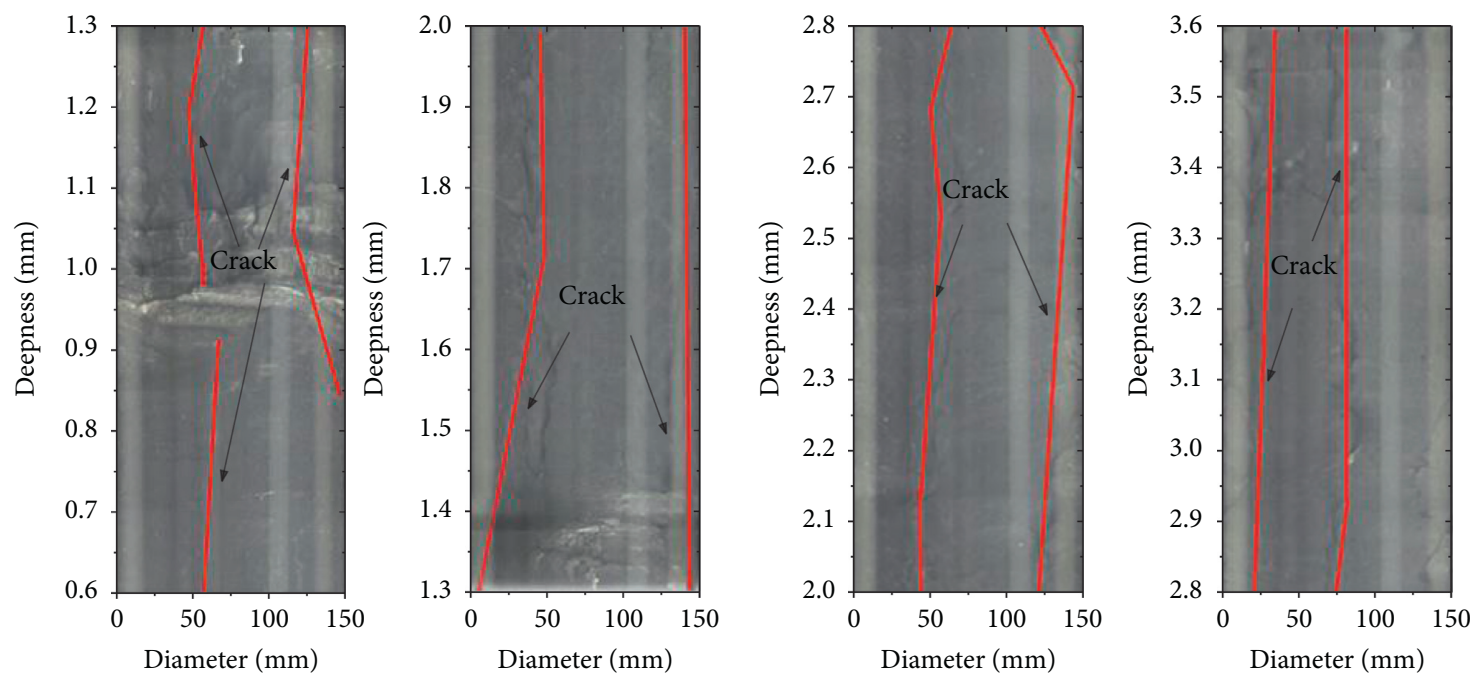

(a)
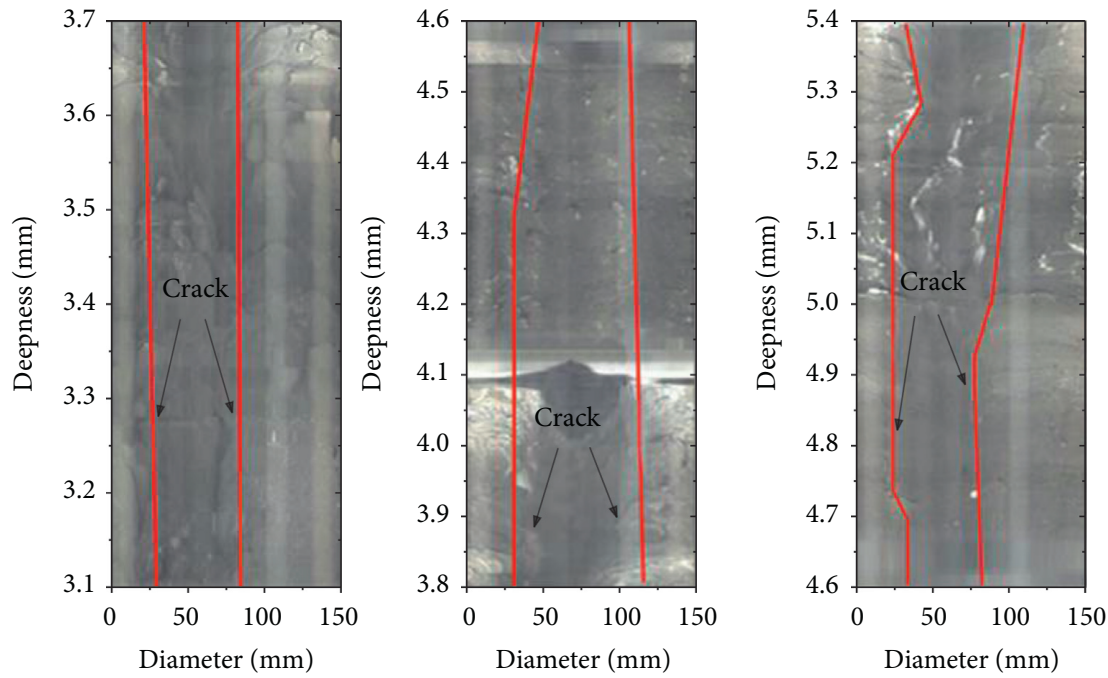

(b)

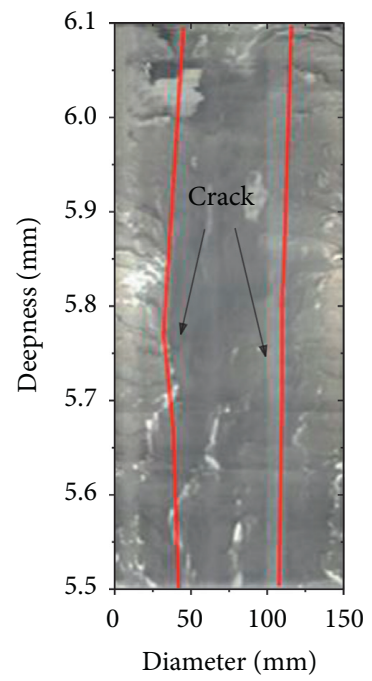

(c)

(d)

FIGURE 14: Crack propagation in the hole after blasting. (a) The first binding energy tube. (b) The second binding energy tube. (c) The third binding energy tube. (d) The fourth binding energy tube. 


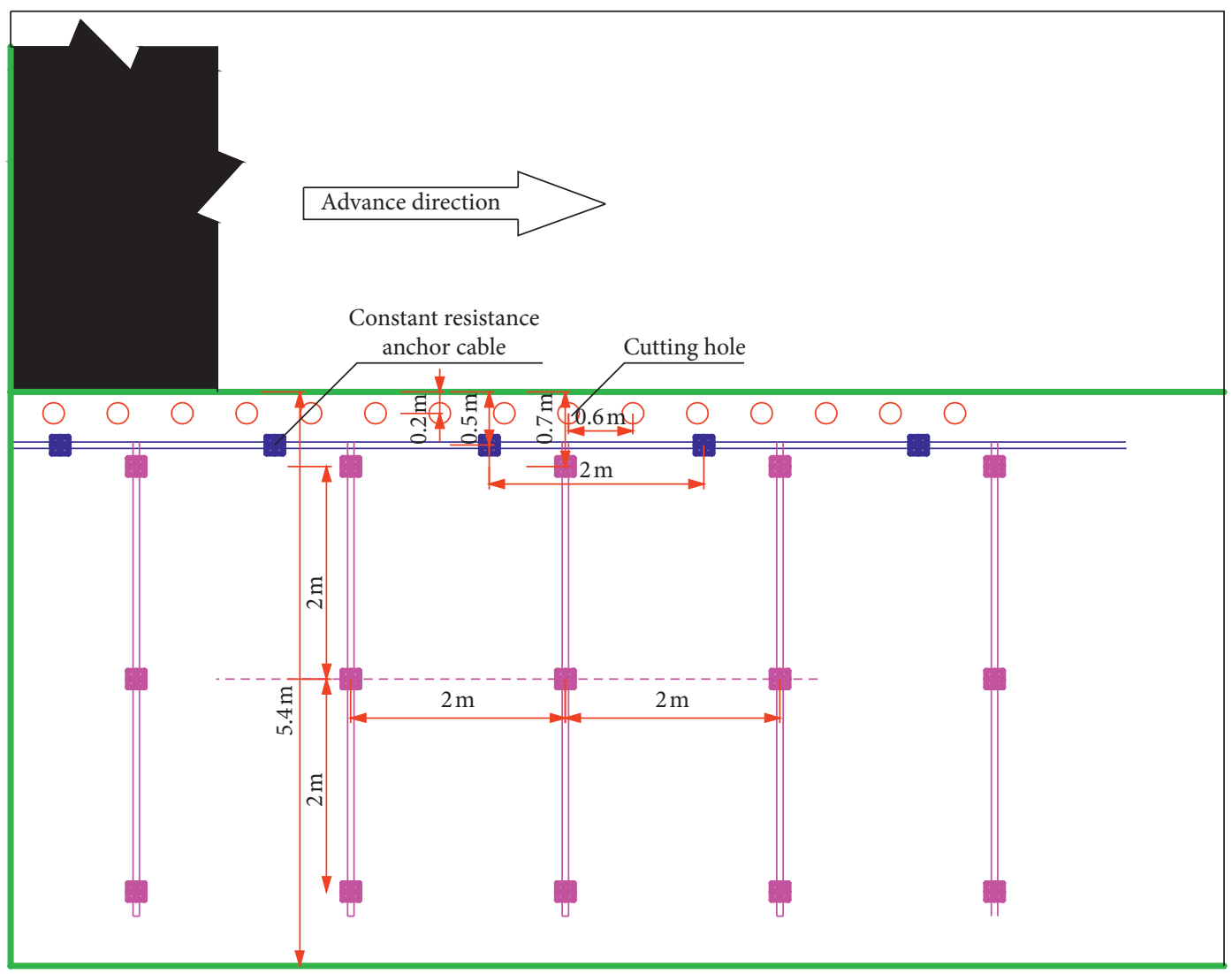

FIGURE 15: Slot hole layout plan.

in the early stage. Then, a continuous hole test was performed to determine the optimal spacing between two adjacent holes. Finally, a single-detonation-number test was conducted to determine the number of optimal detonation blasting holes for one detonation [29]. The cutting height and slit angle have important influence on the success of gob-side entry retaining formed by poof cutting and pressure releasing. The crack propagation in the hole after blasting is shown in Figure 14.

In this study, the optimal charge quantity was set as $3+2+0+1$. The distance between boreholes was $0.6 \mathrm{~m}$. The thickness of boreholes was $6.0 \mathrm{~m}$. The optimal stemming length was $0.5 \mathrm{~m}$. 10 boreholes were generated in each explosion. The borehole layout is as shown in Figure 15.

6.2. Support Parameters. For the 12201 fully mechanized face of Halagou coal mine, as it has a composite roof at a shallow depth, the flap top of the 12201 transport slot becomes relatively long and a large quantity of crushed gangue is generated after the initial weighting in the face, and the fractures in the overlying strata of the goaf run through the surface of the earth because of cyclic weighting. Therefore, in addition to the original support for the 12201 transport slot in Halagou Coal mine, constant resistance large deformation anchor cables should be mounted near the cut line to provide active support, which is aided by a single hydraulic prop, joist steel 11\#, and steel mesh reinforcement. Further, the loose, crushed surrounding rock should be reinforced with grouting bolts. The gaps between the rubbles are filled with grout to build an effective bearing arch with surrounding rock and roadside support and to prevent the gangue in the goaf from overrunning into the roadway. The roadway support is as shown in Figure 16.

The distance between a constant resistance anchor cable and a borehole is $0.35 \mathrm{~m}$, while the distance between anchor cables is $2.0 \mathrm{~m}$. The adjacent anchor cables are connected with $\pi$ steel strips. The roadway support elevation is shown in Figure 17. The distance between the gangue retaining structure and the joist steel $11 \#$ is $0.6 \mathrm{~m}$. The row spacing of gangue retaining monomers is $0.6 \mathrm{~m}$. The wire mesh has a grid size of $0.04 \mathrm{~m} \times 0.04 \mathrm{~m}$.

A remote monitoring system was used to monitor the stress condition of the constant resistance anchor cables on the GER roof. Anchor cables 11\# and 12\# were selected for monitoring and data analysis. These anchor cables were $381 \mathrm{~m}$ and $331 \mathrm{~m}$ away from the 12201 face and the cutting hole. As shown in Figure 18, the stress on anchor cables 11\# and 12\# increases when the lag distances are $-13 \mathrm{~m}$ and $-63 \mathrm{~m}$. As the face continues to advance, the stress remains stable. Therefore, constant resistance large deformation anchor cables play an effective role in facilitating RCPR GER by providing active support on the side of the cutting slot.

As for the layout of grouting bolts, each section has three grouting bolts, with the row distance of $0.8 \mathrm{~m}$. The grouting holes and the wall of the roadway form an angle of 90 degrees, as shown in Figure 19. The grouting material is the 


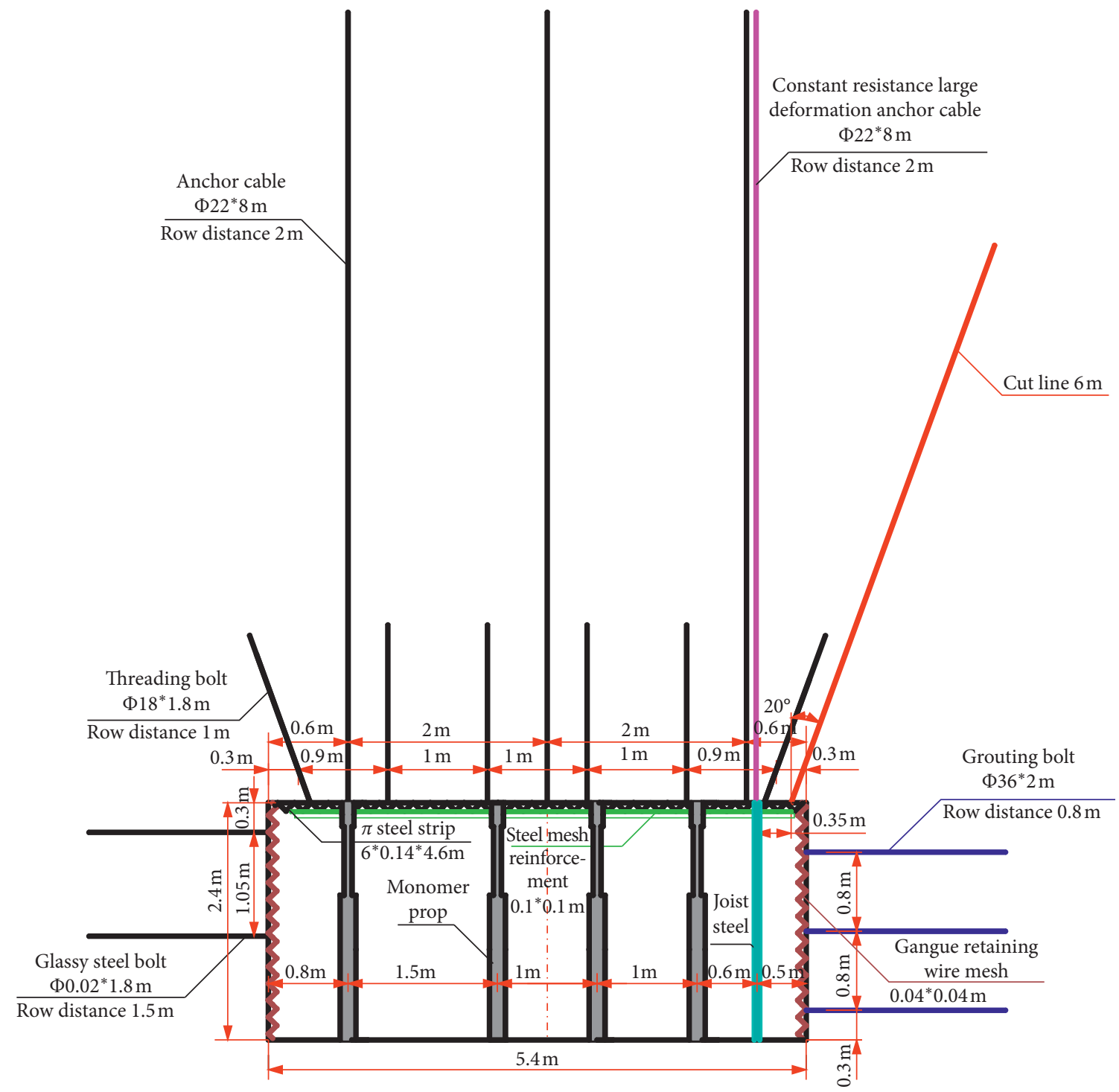

FIGURE 16: Roadway support section.

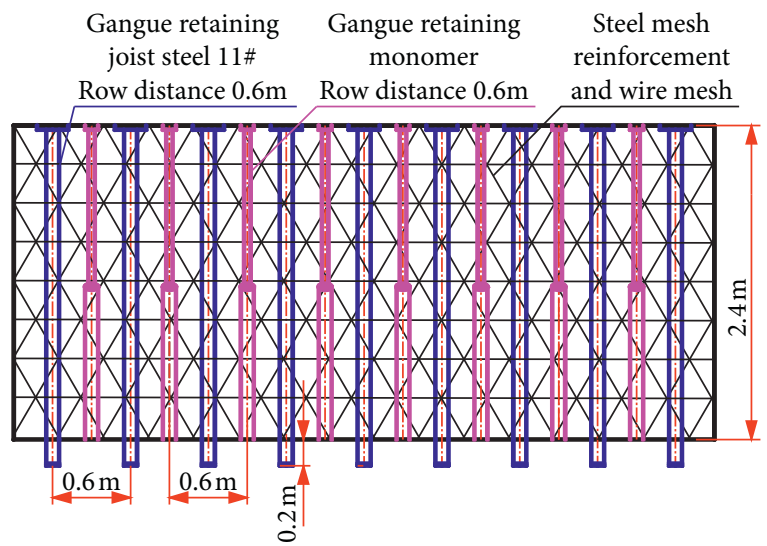

Figure 17: Roadway support elevation.

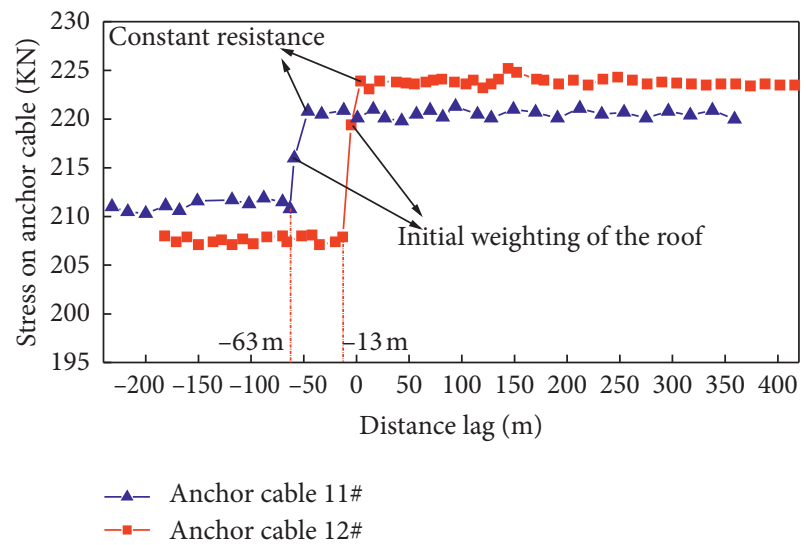

FIGURE 18: Stress curves of anchor cables. 


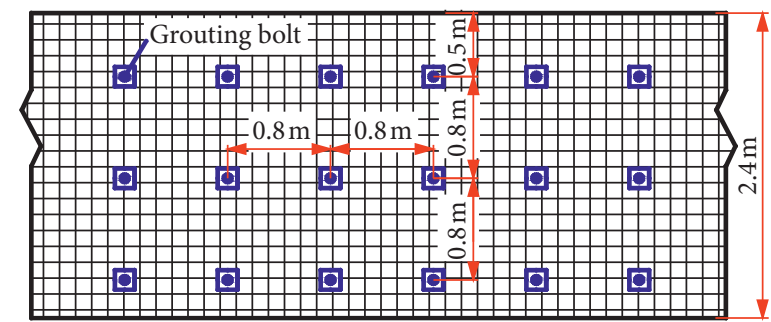

FIGURE 19: Elevation of grouting bolts in the wall of roadway.

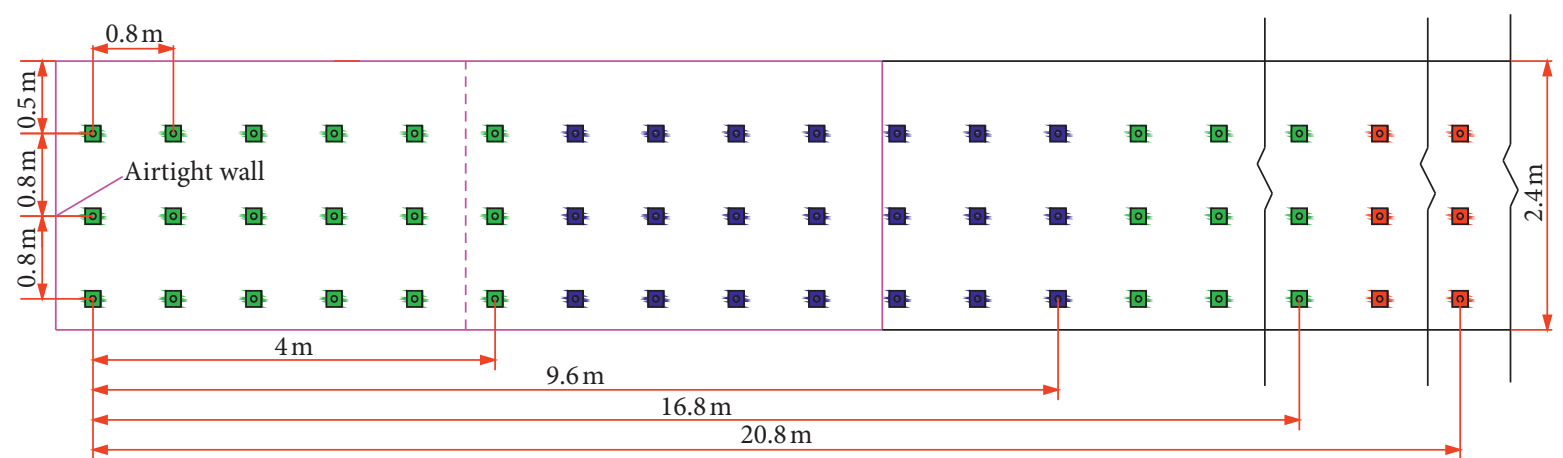

Average grouting volume: $250 \mathrm{~kg}$ cement (bolt)

Average grouting volume: $200 \mathrm{~kg}$ cement (bolt)

Average grouting volume: $100 \mathrm{~kg}$ cement (bolt)

Figure 20: Layout of grouting bolts.

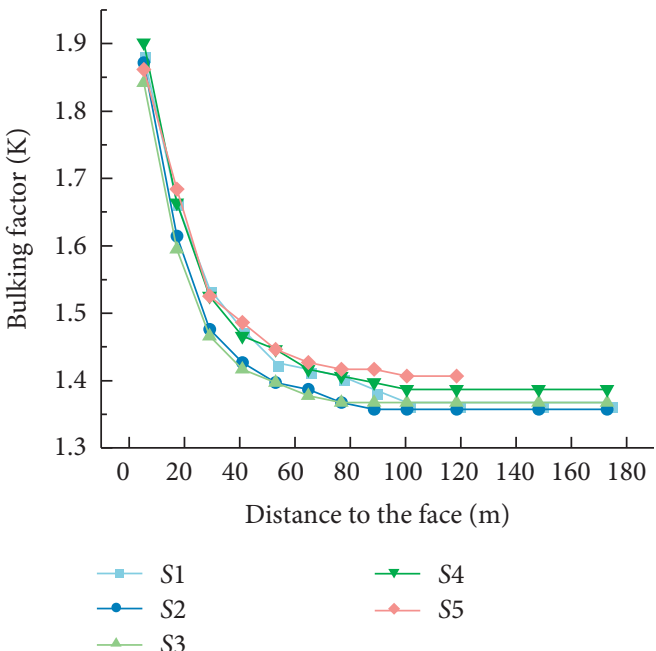

(a)

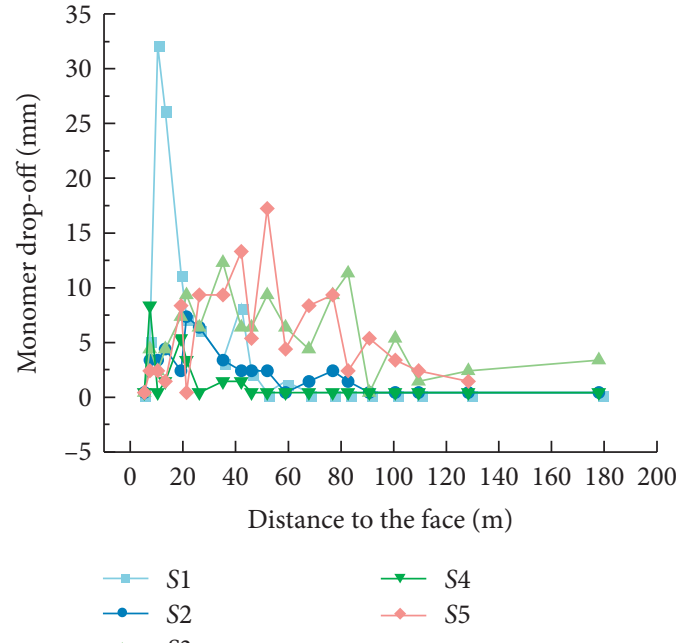

(b)

FIGURE 21: Bulking factors and monomer drop-offs during the mine face's advance. (a) Bulking faction. (b) Monomer drop-off.

mixture of cement, water, and water glass, which is poured from bottom to top. The grouting starts from the entry toward the airtight wall. The grouting volume is shown in Figure 20.

The roof of the 12201 fully mechanized face is mainly composed of siltstone and mudstone. When the goaf is stabilized after the initial caving, the caving height $\left(h_{i}\right)$ of the mudstone in the roadway should be measured. On this basis, the bulking factor $K$ can be determined using

$$
K=\frac{h_{i}}{h_{0}} .
$$

Measuring points $S 1-S 5$ were set up in $50 \mathrm{~m}$ behind the face, with the distance between the measuring points of 
$10 \mathrm{~m}$. As shown in Figure 20, the bulking factor of each measuring point changes as the face advances. Specifically, the bulking factors decrease over time and eventually stabilize in the range between 1.35 and 1.40 . When a bulking factor remains stable, the distance between the face and the corresponding measuring point falls between $60 \mathrm{~m}$ and $110 \mathrm{~m}$. Also, the monomer drop-off of each measuring point decreases and becomes stable as the face moves forward. When a monomer drop-off remains at a stable level, the distance between the face and the corresponding measuring point ranges from $60 \mathrm{~m}$ to $110 \mathrm{~m}$, which is consistent with the bulking factor curve. In another words, the reinforcement of loose, crushed surrounding rock in the gangue retaining structure using grouting bolts further improves the overall stability of the surrounding rock in the gangue retaining structure, which improves the support performance and exerts satisfactory wall control. Bulking factors and monomer drop-offs during the mine face's advance are shown in Figure 21.

\section{Conclusion}

(1) A hard roof mechanical model was developed for mechanical analysis of roof deformation in the RCPR GER process. It was found that the goaf roof was constantly in motion when the face moved toward and crossed the cut line. In this stage, roadway surrounding rock support should be implemented strictly to ensure smooth GER operation.

(2) Based on the analysis of key parameters of automatic roadway with RCPR, the influence of height and angle of roof cutting on the strata behaviors has been simulated and studied with the FLAC3D numerical simulation software, which confirmed that the optimal roof cutting height and splitting angle of the 12201 working face of Halagou Coal mine are $6 \mathrm{~m}$ and $20^{\circ}$, respectively. The effect of automatic roadway with RCPR has been well implemented through conducting the bidirectional cumulative blasting test on site.

(3) The stress concentration area inside the coal side of the roadway has been gradually away from the roadway side due to the increase of the roof cutting height. The decreased vertical displacement of the roadway roof contributes to the stability of the roadway. The displacement distance of the stress concentration area to the core of the coal side has been increased with the increase of the roof cutting angle. But in that case, interaction between the roof above goaf and it above roadway would be weakened. Meanwhile, the length of the short beam of the roadway roof has been increased, resulting in the increased vertical displacement of the roadway roof. There is an extreme angle of $20^{\circ}$ in the roof cutting pressure relief. As the peak curve of stress concentrating on both sides of the extreme angle is decreased, increasing the cutting roof angle can be unfavorable to the management of roadway roof.
(4) Based on the roadway surrounding rock support of the 12201 fully mechanized face of Halagou Coal mine during RCPR GER, when the face approaches the cut line, active support should be provided by adding constant resistance large deformation anchor cables, which should be aided with the rear support given by a single hydraulic prop, joist steel 11\#, and steel mesh reinforcement. Meanwhile, loose and crushed surrounding rock in the gangue retaining structure should be reinforced using grouting bolts. With the effective roadway surrounding rock support during RCPR, gob-side entry retaining and coal pillar-free mining were implemented successfully. The technique can hopefully facilitate operations concerning RCPR of coal-bearing roof structures at a shallow mining depth.

\section{Nomenclature}

$M_{p}: \quad$ Reaction torque of a prop in the roadway $(\mathrm{N} \cdot \mathrm{m})$

$J$ : $\quad$ Moment of inertia of the block rotating around point $\mathrm{O}\left(\mathrm{kg} \cdot \mathrm{m}^{2}\right)$

$L_{0}: \quad$ Fracture in the coal wall $(\mathrm{m})$

$g: \quad$ Gravitational acceleration $\left(\mathrm{m} / \mathrm{s}^{2}\right)$

$M(x)$ : Moment $(\mathrm{N} \cdot \mathrm{m})$

$J_{\mathrm{d} x}$ : Rotational moment of inertia of $\mathrm{dx}$ rotating around the centroid $(\mathrm{m})$

$W: \quad$ Moment of inertia (N)

$L_{\mathrm{Q}}: \quad$ Roof cutting height $(\mathrm{m})$

$\mathrm{H}_{2}$ : Sinkage of the roof $(\mathrm{m})$

$\mathrm{H}_{3}$ : Bottom drum volume (m)

$K$ : $\quad$ Bulking factor, 1.3-1.5

$h_{i}: \quad$ Collapse height of mudstone $(\mathrm{m})$

$h_{0}$ : Mudstone thickness $(\mathrm{m})$

$M: \quad$ Load torque of the roof $(\mathrm{N} \cdot \mathrm{m})$

$L: \quad$ Length of the cantilever beam (m)

$q$ : $\quad$ Uniform load borne by the hard roof $(\mathrm{N})$

$L_{R}: \quad$ Entry retaining width (m)

$Q(x)$ : Shear $(\mathrm{N})$

$T: \quad$ Thickness of the cantilever beam (m)

$P_{n}$ : $\quad$ Support reaction of the breaker prop (N)

$H_{1}$ : Mining height (m).

Greek symbols

$\varepsilon$ : Rotational acceleration of the block rotating around point $\mathrm{O}\left(\mathrm{s}^{-2}\right)$

$\sigma: \quad$ Tensile stress applied to the rock beam $(\mathrm{Pa})$

$[\sigma]$ : Ultimate tensile strength of the roof $(\mathrm{MPa})$

$\tau$ : Friction $(\mathrm{N})$.

\section{Data Availability}

The data used to support the findings of this study are available from the corresponding author upon request.

\section{Conflicts of Interest}

The authors declare no conflicts of interest. 


\section{Acknowledgments}

This work was supported by Liaoning Provincial Education Department Fund (LJ2017FAL002), Liaoning Innovation and Entrepreneurship Training Plan for College Students (2017101470001), and China Postdoctoral Science Foundation (2020M680490).

\section{References}

[1] M. G. Qian, P. W. Shi, and J. L. Xu, Mine Pressure and Rock Formation Control, Xuzhou China University of Mining and Technology Press, Beijing, China, 2010.

[2] M. G. Qian and X. X. Miao, "Formation and stress analysis of over-lying strata structure in stope," Journal of Rock Mechanics and Engineering, vol. 14, no. 2, p. 97, 1995.

[3] Y. Xue, "From tradition to modern times: evolution of coal mining technology in China," Journal of Hubei Polytechnic University (Humanities and Social Science), vol. 30, no. 5, pp. 7-15, 2013.

[4] G. F. Zhang, M. C. He, and X. P. Xu, "Research on mining technology of coal pillar without cutting along the goaf in Baiji Mine protective layer," Journal of Mining \& Safety Engineering, vol. 28, no. 4, pp. 511-516, 2011.

[5] J. W. Wang, S. B. Wang, and J. Yang, "Failure mechanism and control technology of roof retaining in retaining roadway with cut-out pressure," Journal of Coal Science and Technology, vol. 45, no. 8, pp. 80-84, 2017.

[6] Y. Chen, S. P. Hao, and Y. T. Chen, "Application of shallow hole blasting with pilot holes in pressure relief of retaining roadway," Journal of Mining \& Safety Engineering, vol. 32, no. 2, pp. 253-259, 2015.

[7] X. Ma, M. He, J. Wang, Y. Gao, D. Zhu, and Y. Liu, "Mine strata pressure characteristics and mechanisms in gob-side entry retention by roof cutting under medium-thick coal seam and compound roof conditions," Energies, vol. 11, no. 10, p. 2539, 2018.

[8] M. C. He, Z. Q. Song, and A. Wang, "Theory of longwall mining by using roof cutting shortwall teamand 110 method: the third minging scienceand technology reform," Coal Science \& Technology Magazine, vol. 45, no. 1, pp. 1-9, 2017.

[9] Y. Zhang, N. N. Liang, and B. Zhao, "Roof cutting and pressure re-leasing and gob-side roadway forming technology in fully mechanized face of deep seam," Coal Mine Safety, vol. 48, no. 9, pp. 92-95, 2017.

[10] E. L. Xue, Z. H. Ma, and W. Luo, "Study on the mining pressure law of automatic roadway with shallow top-buried composite roof along the empty cutting roof," Coal Science and Technology, vol. 45, no. S1, pp. 34-38, 2017.

[11] Y. B. Gao, Z. B. Guo, and J. Yang, "Steady-state analysis of surrounding rock structure along the empty-cut roadway and coordinated control of constant pressure yielding," Journal of China Coal Society, vol. 42, no. 7, pp. 1672-1681, 2017.

[12] S. Bjurstrom, "Shear strength of hard rock joints reinforced by grouted untensioned bolts," in Proceedings of the 3rd Congress, ISRM Denver, vol. 2, Denver, CO, USA, September 1974.

[13] M. C. He, Y. J. Wang, and J. Yang, "Comparative analysis of stress field distribution characteristics of self-formed roadway and conventional mining with no-column unloading coal pillars," Journal of China Coal Society, vol. 43, no. 3, pp. 626-637, 2018.

[14] M. C. He, Y. B. Gao, and J. Yang, "Gathering and slitting technology of self-forming tunnel without coal pillar and its influence on stress evolution of surrounding rock," Chinese
Journal of Rock Mechanics and Engineering, vol. 36, no. 6, pp. 1314-1325, 2017.

[15] J. Hematian, I. Porter, and N. I. Aziz, "Design of roadway support using a strain softening model," in Proceedings of the 13th International Conference on Ground Control in Mining, pp. 50-57, Morgantown, WV, USA, August 1994.

[16] M. Lars, Interaction of Shotcrete with Rock and Rock Bolts, ScienceDirect, Amsterdam, Netherlands, 2007.

[17] S. K. Palei and S. K. Das, "Sensitivity analysis of support safety factor for predicting the effects of contributing parameters on roof falls in underground coal mines," International Journal of Coal Geology, vol. 75, no. 4, pp. 241-247, 2008.

[18] N. G. Baxter, T. P. Watson, and B. N. Whittaker, "A study of the application of T-H support systems in coal mine gate roadways in the UK," Mining Science and Technology, vol. 10, no. 2, pp. 167-176, 1990.

[19] S. Huang, Y. Lv, Y. Peng, and L. Zhang, "Tunnel stability and deformation analysis under excavation load," IOP Conference Series: Earth and Environmental Science, vol. 153, no. 4, p. 042004, 2018.

[20] M. C. He, S. Y. Chen, and Z. B. Guo, "Control of surrounding rock structure and its engineering application in the roadway with cut-off pressure and residual space," Journal of China University of Mining \& Technology, vol. 46, no. 5, pp. 959-969, 2017.

[21] M. C. He, W. F. Cao, and R. L. Shan, "New technology of biaxial shaped charge tensile blasting," Journal of Rock Mechanics and Engineering, vol. 22, no. 12, p. 2047, 2003.

[22] M. C. He, P. F. Guo, and X. H. Zhang, "Directional presplitting of roadway roof based on the theory of bidirectional shaped energy drawing blasting," Explosion and Impact, vol. 38, no. 4, pp. 795-803, 2018.

[23] X. M. Sun, X. Liu, and G. F. Liang, "Key parameters of gobside entry retaining formed by roof cut and pressure releasing in thin coal seams," Chinese Journal of Rock Mechanics and Engineering, vol. 33, no. 7, pp. 1449-1456, 2014.

[24] Z. B. Guo, J. Wang, and T. P. Cao, "Tesearch on key parameters of gob-side entry retaining automatically formed by roof cutting and pressure release in thin coal seam mining," Journal of China University of Mining \& Technology, vol. 45, no. 9, pp. 879-885, 2016.

[25] M. C. He and Z. B. Guo, "Mechanical properties of constant resistance large deformation anchor and its engineering application," Chinese Journal of Rock Mechanics and Engineering, vol. 33, no. 7, pp. 1297-1308, 2014.

[26] H. L. Cai, X. K. Yin, and C. J. Tang, "Research and application of coal pillar-less mining technology with roof cutting and pressure relief and gob-side entry retaining," Mining Safety and Environmental Protection, vol. 39, no. 5, pp. 15-18, 2012.

[27] M. C. He, W. F. Cao, and R. L. Shan, "New blasting technology-bilateral cumulative tensile explosion," Chinese Journal of Rock Mechanics and Engineering, vol. 22, no. 12, pp. 2047-2051, 2003.

[28] X. G. Ma, M. C. He, and Z. Li, "Key Parameters of gob-side entry retaining automatically formed by roof cutting and blasting in compound roof condition," Journal of China University of Mining \& Technology, vol. 48, no. 2, pp. 236-246, 2019.

[29] G. Williams, Roof Bolting in South Wales, Colliery Guardian, London, UK, 2004. 